\title{
CTLA4 gene polymorphisms are associated with chronic bronchitis
}

\author{
G. Zhu*, A. Agusti ${ }^{\#, \uparrow,+}$, A. Gulsvik ${ }^{\S}$, P. Bakke ${ }^{\S}$, H. Coxson ${ }^{f}$, D.A. Lomas**, \\ E.K. Silverman ${ }^{\# \#}$, S.G. Pillai* and ICGN investigators ${ }^{\text {Iथ }}$
}

ABSTRACT: Chronic obstructive pulmonary disease (COPD) is characterised by chronic and progressive dyspnoea, cough and sputum production. T-lymphocytes may play a key role in the pathogenesis of COPD and chronic bronchitis. Cytotoxic T-lymphocyte antigen (CTLA) 4 is a potential candidate gene because it modulates T-cell activation.

Genetic association between nine CTLA4 single nucleotide polymorphisms (SNPs) and chronic bronchitis was assessed in 606 pedigrees (1,896 individuals) from the International COPD Genetics Network (ICGN) population. We then replicated the associations in 342 COPD subjects with chronic bronchitis and 511 COPD subjects without chronic bronchitis from Bergen, Norway. Family-based association tests were used to analyse the ICGN cohort, and a logistic regression model was used for the Bergen cohort.

Six CTLA4 SNPs were significantly associated with chronic bronchitis in the ICGN cohort $(0.0079 \leqslant p \leqslant 0.0432)$, with three being replicated with the same directionality of association in the Bergen cohort $(0.0325 \leqslant p \leqslant 0.0408)$. One of these replicated SNPs (rs231775) encodes the Thr to Ala substitution at amino acid position 17. Haplotype analyses supported the results of single SNP analyses.

Thus, CTLA4 is likely to be a genetic determinant of chronic bronchitis among COPD cases.

KEYWORDS: Chronic bronchitis, chronic obstructive pulmonary disease, genetic association, replication, smoking, tobacco

hronic obstructive pulmonary disease (COPD), one of the leading causes of death in developed countries, is characterised by progressive and poorly reversible airflow limitation [1]. Cigarette smoking is the main environmental risk factor for COPD, but only a minority of individuals who smoke cigarettes develop the disease [2,3]. Twin studies and familial aggregation studies demonstrated that a genetic component is likely to be an important determinant of COPD susceptibility [4-8]. Genome-wide linkage analysis of the Boston Early-Onset COPD Study families showed a significant linkage peak for the airflow limitation on chromosome $2 q$ [9-11]. Linkage to this same region of chromosome $2 \mathrm{q}$ to airflow limitation in general population pedigrees has also been demonstrated [12].

The chronic airflow limitation that is characteristic of COPD is caused by a mixture of small airway disease and emphysema and is often accompanied by chronic bronchitis [1]. The activation and proliferation of T-lymphocytes is likely to be involved in the pathogenesis of COPD and chronic bronchitis, and the numbers of Tcells are correlated with the amount of alveolar destruction and the severity of airflow obstruction [13-16]. Activating naive T-cells requires the presence of the antigen and co-stimulatory molecules B7-B7.1 (CD80) and B7.2 (CD86) on antigen-presenting cells. The receptor on the Tcell for B7 is CD28. Activated T-cells express an additional receptor, the cytotoxic T-lymphocyte antigen (CTLA) 4, which binds to B7 with a much higher affinity than CD28 [17] and plays a potent role in downregulation of T-cell activation [18]. CTLA4 is induced following T-cell receptor (TCR)/CD28 stimulation; it arrests activated Tcells, thereby keeping them in an anergic state. Arrested T-cells exit the lymph nodes and enter the circulation [19]. Blocking CTLA4 can intensify $\mathrm{T}$-cell responses and exacerbate autoimmune disease [20]; CTLA4-deficient mice die by 34 weeks of age due to multi-organ lymphocytic infiltration and tissue destruction [17]. CTLA4,
AFFILIATIONS

*Genetics, GlaxoSmithKline, Research and Development, Research Triangle Park, NC, \#\#Brigham and Women's Hospital, Boston, MA, USA.

\#Hospital Universitario Son Dureta, Palma de Mallorca,

'Fundación Caubet-Cimera, Bunyola, Mallorca,

+Institut del Tòrax, Hospital Clínic, Universitat de Barcelona, Barcelona, Spain.

§University of Bergen, Bergen, Norway.

${ }^{f}$ University of British Columbia, Vancouver, BC, Canada. ${ }^{* \star}$ Cambridge Institute for Medical Research, Cambridge, UK. "A list of the ICGN investigators is given in the Acknowledgements section.

CORRESPONDENCE S.G. Pillai

Glaxo SmithKline R\&D

5 Moore Drive

Research Triangle Park

NC 27709

USA

E-mail: pillaisreekumar@yahoo.com

Received:

Sept 152008

Accepted after revision:

April 072009

First published online:

April 222009 
which is located at chromosome $2 \mathrm{q} 33$, has been associated with several inflammatory diseases including asthma [21, 22]. Therefore, CTLA4 is a candidate gene for COPD and/or chronic bronchitis because of its critical effect on inhibiting the activation of T-cells.

As CTLA4 is located near the region on chromosome $2 \mathrm{q}$ that showed significant linkage with COPD-related phenotypes both in the Boston Early-Onset COPD Study [9-11], as well as in general population pedigrees [12], we hypothesised that CTLA4 single nucleotide polymorphisms (SNPs) would be associated with COPD and COPD-related phenotypes, including the severity of airflow limitation and the presence of chronic bronchitis.

\section{METHODS}

\section{Study design}

The present study is a two-phase study. First, we explored whether CTLA4 SNPs were associated with COPD and COPDrelated phenotypes in a subset of the International COPD Genetics Network (ICGN) population, a large cohort of COPD probands $(n=606)$ and siblings $(n=1,285)$, whose methodological details have been described elsewhere [23-25]. Secondly, we attempted to replicate our findings in an independent population that included COPD cases $(n=953)$ and controls $(\mathrm{n}=956)$ recruited in Bergen (Norway), whose characteristics have also been reported [23, 25].

\section{Populations and assessment}

The clinical characteristics of the subjects in both cohorts included in the analysis of the chronic bronchitis phenotype are shown in table 1 . Subject recruitment and clinical characteristics have been described previously [23-25]. Briefly, the first population represents the multicentre ICGN study; subjects with known COPD were recruited as probands, and siblings and available parents were ascertained through the probands. Inclusion criteria for probands were airflow limitation (post-bronchodilator forced expiratory volume in $1 \mathrm{~s}$ (FEV1) $<60 \%$ predicted and FEV1/vital capacity (VC) $<90 \%$ pred) at a relatively early age (45-65 yrs), a smoking history of $\geqslant 5$ pack-yrs, and at least one eligible sibling (with a smoking history of $\geqslant 5$ pack-yrs). COPD in siblings was defined by a post-bronchodilator FEV1 $<80 \%$ pred and FEV1/VC $<90 \%$ pred (generally consistent with Global Initiative for Chronic Obstructive Lung Disease (GOLD) stage II or greater). 606 pedigrees with 1,896 Caucasian individuals were genotyped in this analysis. Chronic bronchitis was defined as chronic cough and sputum production for $\geqslant 3$ months $\cdot \mathrm{yr}^{-1}$ for the past 2 yrs. Among the 1,193 COPD cases of the ICGN subjects analysed, $471(39.5 \%)$ had chronic bronchitis.

The cohort recruited in Bergen included COPD cases and controls; all subjects were either current or ex-smokers with $\geqslant 2.5$ pack-yrs of smoking history. COPD was diagnosed if post-bronchodilator FEV1 was $<80 \%$ pred with FEV1/forced vital capacity $(\mathrm{FVC})<0.7$. Controls were selected on the basis of FEV $1>80 \%$ pred and FEV1/FVC $>0.7$. A total of 953 COPD cases and 956 controls were included. Out of the 953 cases with COPD, there were 342 (35.9\%) with and 511 (53.6\%) without chronic bronchitis.

\section{SNP selection}

Linkage disequilibrium (LD) tagging of CTLA4 SNPs was performed using an $\mathrm{r}^{2}$ threshold of 0.8 for the SNP selection with a pairwise method in the Haploview program [26]. The tagging SNP selection was based on HapMap data for EuropeanAmericans (US residents with northern and western European ancestry, i.e. CEPH (Centre d'Etude du Polymorphisme Humain) samples from Utah (CEU)) with a minor allele frequency $>5 \%$ from the public database [27]. Accordingly, nine SNPs in CTLA4 region were selected. These SNP locations and characteristics are summarised in table 2.

\section{Genotyping}

Genotyping in the two cohorts was performed with the Illumina array-based custom SNP genotyping platform (Illumina Inc., San Diego, CA, USA). Deviation from HardyWeinberg equilibrium for each SNP was assessed in controls by using the goodness-of-fit test with SAS software version 8.2 (SAS Institute, Inc., Cary, NC, USA); Hardy-Weinberg equilibrium for each SNP was also tested in the family data using PBAT version 3.5 (Golden Helix Inc, Bozeman, MT, USA) [28].

TABLE 1 Clinical characteristics of patients with and without chronic bronchitis $(\mathrm{CB})$ in the chronic obstructive pulmonary disease (COPD) cases of the International COPD Genetics Network (ICGN) study and the Bergen cohort

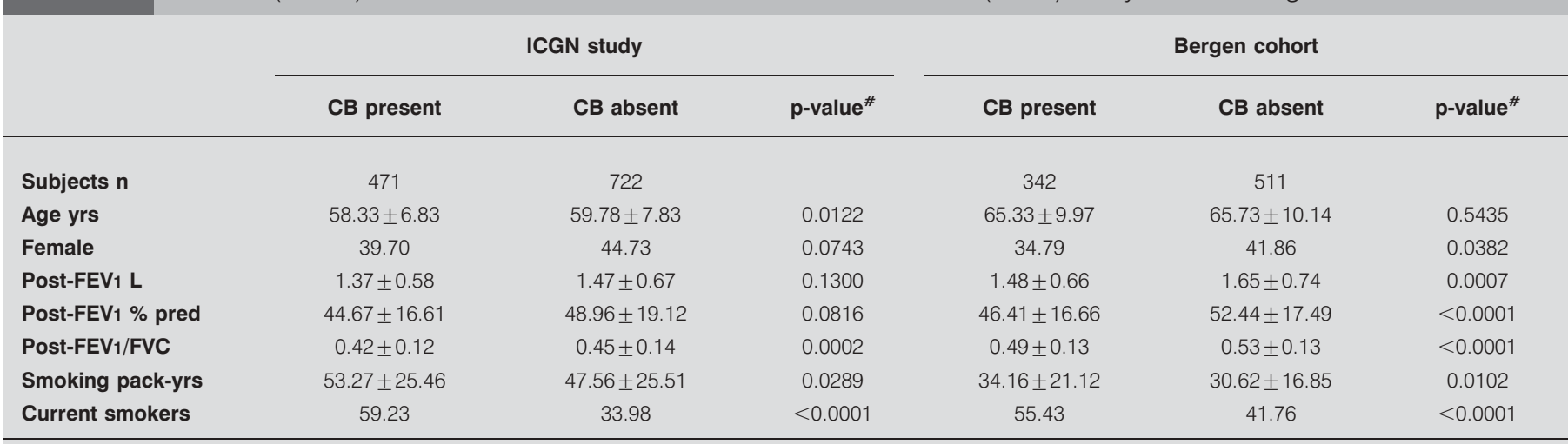

Data are presented as mean \pm SD or $\%$, unless otherwise indicated. Post-FEV1: post-bronchodilator forced expiratory volume in $1 \mathrm{~s} ; \%$ pred: \% predicted; FVC: forced vital

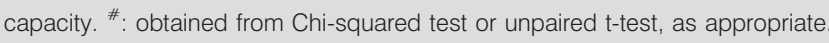




\begin{tabular}{|c|c|c|c|c|c|c|c|}
\hline TABLE & $\begin{array}{l}\text { Single nucl } \\
\text { Genetics N } \\
\text { the CTLA4 }\end{array}$ & $\begin{array}{l}\text { olymorpr } \\
\text { CGN) far }\end{array}$ & $\begin{array}{l}\text { SNPs) genc } \\
\text { ta and Berge }\end{array}$ & $\begin{array}{l}\text { in the } \\
\text { onic ob }\end{array}$ & $\begin{array}{l}\text { lational Chror } \\
\text { ive pulmonar }\end{array}$ & $\begin{array}{l}\text { ostructive pulm } \\
\text { ease (COPD) }\end{array}$ & $\begin{array}{l}y \text { disease } \\
\text { and controls in }\end{array}$ \\
\hline 1 & rs926169 & & 204430997 & $\mathrm{G} / \mathrm{T}$ & 0.385 & 0.500 & 0.496 \\
\hline 3 & rs11571316 & Promoter & 204439334 & $\mathrm{C} / \mathrm{T}$ & 0.444 & 0.382 & 0.377 \\
\hline 4 & rs16840252 & Promoter & 204439764 & $\mathrm{C} / \mathrm{T}$ & 0.183 & 0.166 & 0.156 \\
\hline 5 & rs231775 & Thr/Ala & 204440959 & $\mathrm{~A} / \mathrm{G}$ & 0.369 & 0.427 & 0.441 \\
\hline 6 & rs231777 & Intron & 204441833 & $\mathrm{C} / \mathrm{T}$ & 0.163 & 0.145 & 0.144 \\
\hline 7 & rs231779 & Intron & 204442732 & $\mathrm{C} / \mathrm{T}$ & 0.368 & 0.425 & 0.441 \\
\hline 8 & rs3087243 & $3^{\prime}$ flank & 204447164 & $A / G$ & 0.469 & 0.404 & 0.401 \\
\hline
\end{tabular}

All CTLA4 SNPs (p-values >0.05) were in Hardy-Weinberg equilibrium in both the family data and the control data. Mendelian inheritance was assessed in the family data using the PedCheck program [29], and individuals with pedigree inconsistencies for a particular SNP were removed from analysis.

\section{Statistical analysis}

In the ICGN study, we used Family-based Association Test (FBAT) version 1.7.3 [30] to analyse single-SNP associations with COPD and chronic bronchitis (qualitative phenotypes). The analyses of quantitative traits (FEV1 and FEV1/VC) were performed with covariates including centre, age, sex, height and pack-yrs of cigarette smoking using PBAT version 3.5 (Golden Helix Inc, Bozeman, MT, USA) [28]. We performed analyses using an additive genetic model in order to reduce multiple statistical testing. The additive model is equivalent to the classic transmission disequilibrium test. The risk allele was determined from the FBAT Z statistic. Values of $\mathrm{p}<0.05$ from the association analyses were considered nominally significant. We estimated the number of independent SNPs for nine SNPs using the SNP spectral decomposition (SNPSpD) approach [31], and five SNPs were found to be independent. Thus, the adjusted significant $\mathrm{p}$-value is $<0.01$ (i.e. $0.05 / 5$ ) after correction for multiple testing. For the ICGN families, haplotypes were inferred and assessed using the HBAT command of the FBAT software with the use of Monte Carlo sampling [32]. A minimum of 10 informative families were analysed using both FBAT and HBAT. Using a SNP sliding window approach (adjacent sets of two and three SNPs), the results of global and haplotype-specific association statistics were determined. Values of $\mathrm{p}<0.05$ from the analyses were considered the nominal significant levels. Considering that 15 sliding window haplotypes were evaluated in our study, the adjusted significant p-value is 0.0033 (i.e. $0.05 / 15$ ) based on a global pvalue after Bonferroni correction for multiple testing. In consideration of high correlation among COPD, FEV1, FEV1/ (F)VC and chronic bronchitis phenotypes, we chose not to correct for multiple testing of the phenotypes in order to avoid being over-conservative. For chronic bronchitis data, we used PBAT version 3.5 [28] to estimate the power. At significance level of 0.05 , and penetrances of $0.7,0.4$ and 0.1 for three genotypes, our study had $97.32 \%, 75.20 \%, 97.51 \%, 92.43 \%$, $97.23 \%, 90.52 \%, 97.23 \%, 97.81 \%$ and $96.67 \%$ power to detect association for SNP 1-9, respectively.

In the Bergen cohort, a logistic regression model was used to investigate relationships of CTLA4 SNPs with COPD and chronic bronchitis. Analyses were performed using SAS software 8.2 with an additive genetic model. The odds ratios were estimated using the minor allele as the reference. Haplotype-based analyses were performed using the expectation-maximisation algorithm and score tests as implemented in Haplo.stats software [33]. As we used the Bergen case-control cohort for replication of the confirmed results from the ICGN family-based association analysis, we did not perform correction of multiple testing for the association analysis of both single SNPs and haplotypes. In the Bergen cohort, we estimated an inflation factor $\lambda$ from the genomic control method [34] using a panel of 221 unlinked SNPs genotyped previously and did not detect significant evidence of population stratification; the mean inflation factor of the genomic control SNPs was 1.027 [23].

Visualisation of LD measures in the CTLA4 region was performed with the Haploview program [26]. Haplotype blocks were defined with the confidence interval method described by GABRIEL et al. [35].

\section{RESULTS}

\section{Individual SNP association analyses}

We evaluated nine SNPs in the CTLA4 region; the location and characteristics of those SNPs are summarised in table 2. We did not detect any significant genetic associations of CTLA4 SNPs with the presence/absence of COPD in either the ICGN or the Bergen COPD cases and controls (table E1, online supplemetary material). In addition, there were no significant associations between CTLA4 SNPs and FEV1 or FEV1/(F)VC in either the ICGN families or the Bergen COPD cases (data not shown).

In contrast, we found significant associations with the other COPD-related phenotype investigated, chronic bronchitis. In the ICGN families, six out of the nine CTLA4 SNPs genotyped (SNPs 


\begin{tabular}{|c|c|c|c|c|c|c|c|}
\hline TABLE 3 & $\begin{array}{l}\text { Associati } \\
\text { Internatio } \\
\text { pulmonar }\end{array}$ & $\begin{array}{l}\text { individual } \\
\text { ronic obst } \\
\text { ase cases }\end{array}$ & $\begin{array}{l}\text { TLA4 single nucleot } \\
\text { uctive pulmonary di } \\
\text { of the Bergen study }\end{array}$ & $\begin{array}{l}\text { polymo } \\
\text { se Gen }\end{array}$ & $\begin{array}{l}\text { sms (SNPs } \\
\text { Network }\end{array}$ & $\begin{array}{l}\text { chronic bronchitis } \\
\text { family study and }\end{array}$ & $\begin{array}{l}\text { e in the } \\
\text { ostructive }\end{array}$ \\
\hline SNP ID & SNP name & Risk allele & Informative families $n$ & $\mathrm{p}$-value & Risk allele & Effect estimates & p-value \\
\hline 3 & rs11571316 & C & 176 & 0.0230 & $\mathrm{~T}$ & $0.799(0.649-0.983)$ & 0.0359 \\
\hline 4 & rs16840252 & $\mathrm{T}$ & 100 & 0.4015 & $\mathrm{~T}$ & $0.983(0.762-1.269)$ & 0.8669 \\
\hline 5 & rs231775 & G & 163 & 0.0081 & G & $1.247(1.019-1.526)$ & 0.0325 \\
\hline 6 & rs231777 & $\mathrm{T}$ & 91 & 0.7428 & $\mathrm{~T}$ & $0.886(0.674-1.166)$ & 0.3791 \\
\hline 7 & rs231779 & C & 162 & 0.0112 & C & $1.221(0.998-1.496)$ & 0.0532 \\
\hline
\end{tabular}

rs926169, rs11571316, rs231775, rs231779, rs3087243 and rs231725) were significantly associated with the chronic bronchitis phenotype (table $3 ; 0.0079 \leqslant \mathrm{p} \leqslant 0.0432$ ). Associations with SNPs rs231775 and rs3087243 $(\mathrm{p}=0.0081$ and 0.0079 , respectively) were significant even after a correction for multiple testing.

We replicated the significant association with the chronic bronchitic phenotype in the COPD cases of the Bergen cohort for four of the six CTLA4 SNPs (rs11571316, rs231775, rs3087243 and rs231725; $0.0325 \leqslant \mathrm{p} \leqslant 0.0408$ ) identified in the ICGN study (table 3). After evaluating the risk allele (table 3), we found that three of the replicated significant SNPs (rs231775, rs3087243 and rs231725) for chronic bronchitis have the same directionality of association in the two populations.

We did not detect any significant association with chronic bronchitis in control subjects without COPD in the Bergen cohort (data not shown), suggesting that CTLA4 is associated with chronic bronchitis among COPD subjects.

\section{LD block analysis}

Figure 1 shows pairwise LD $\mathrm{r}^{2}$-values for the nine SNPs in the CTLA4 region. In the ICGN study, we identified two haplotype blocks. Several of the significantly associated SNPs (rs926169, rs11571316, rs231775 and rs231777) were located in block 1, a)
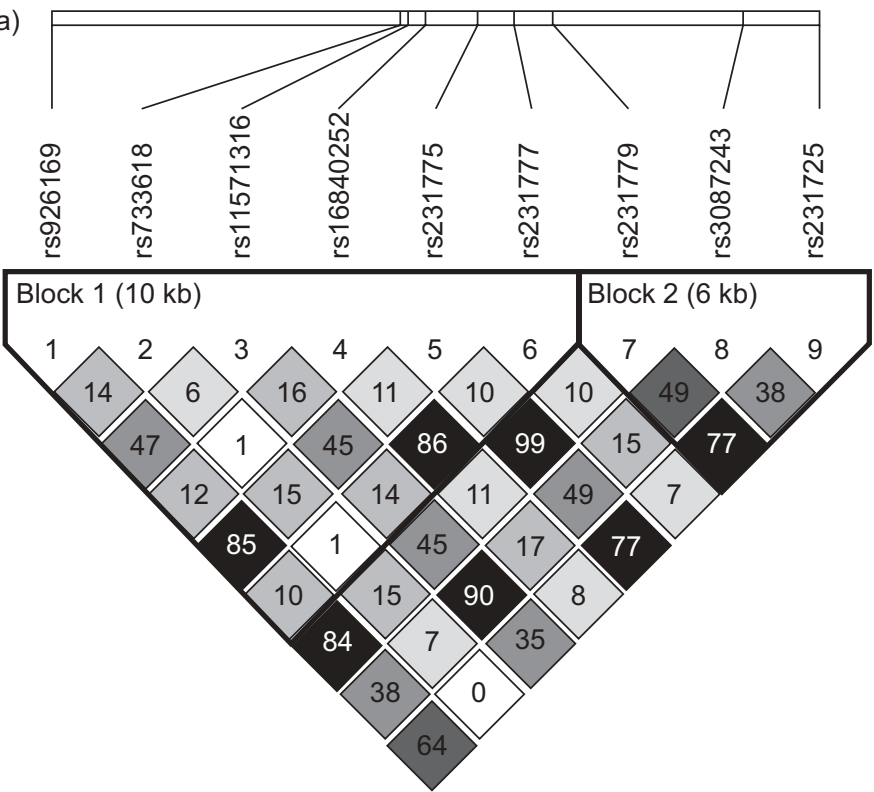

b)
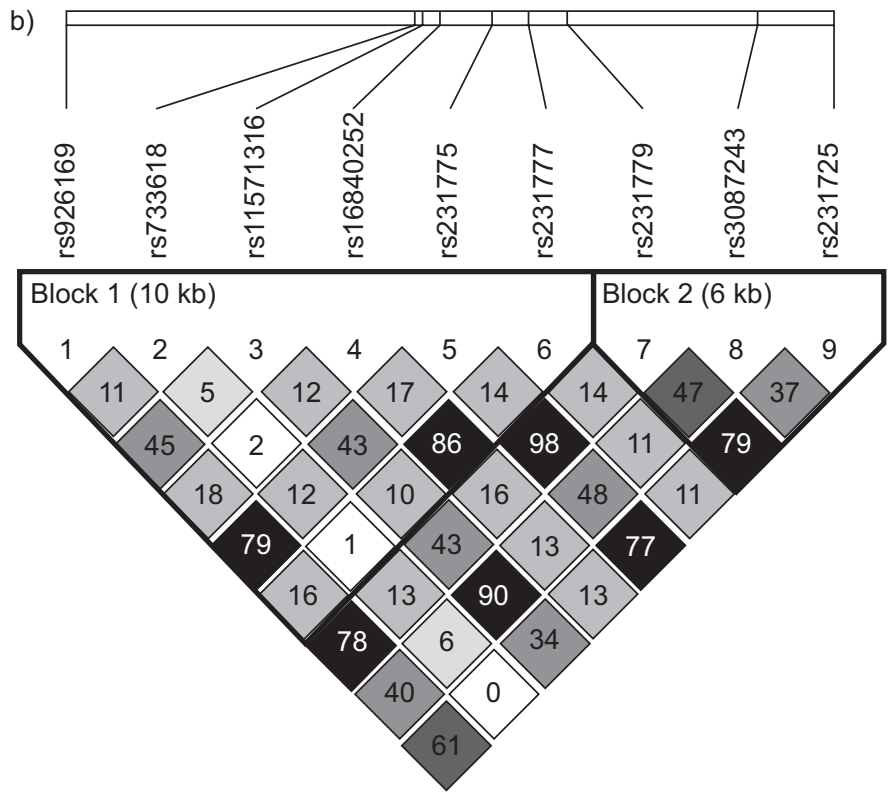

FIGURE 1. Linkage disequilibrium (LD) map across the cytotoxic T-lymphocyte antigen (CTLA) 4 region. Pairwise LD plots of nine single nucleotide polymorphisms (SNPS) within the CTLA4 region in a) the International Chronic obstructive pulmonary disease Genetics Network family-based population and b) the Bergen case-control population. Values of $r^{2}(\times 100)$ are shown. $\mathbf{\square}: r^{2}=1 ; \square: r^{2}=0$; squares in shades of grey: $0<r^{2}<1$ (the intensity of the grey is proportional to $\left.r^{2}\right)$. LD block structure was estimated using the Haploview program. 


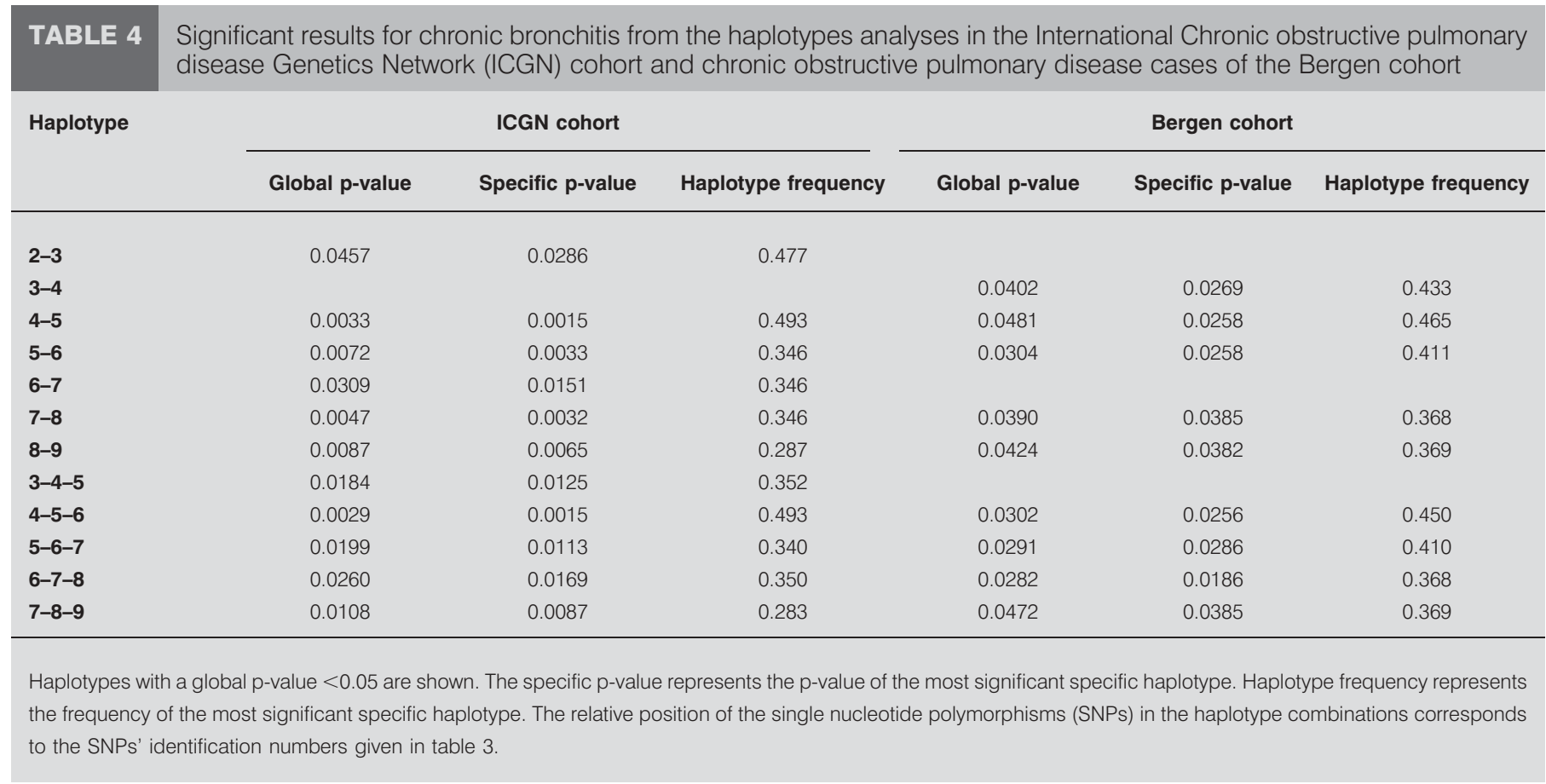

while three other significantly associated SNPs (rs231779, rs3087243 and rs231725) were located in block 2. In block 1, there were strong pairwise correlations between SNPs rs926169 and rs231775 $\left(\mathrm{r}^{2}=0.85\right)$, and between SNPs rs16840252 and rs231777 $\left(r^{2}=0.86\right)$. In the Bergen cohort, the same two haplotype blocks were identified, with SNPs significantly associated with chronic bronchitis in each block.

\section{Haplotype association analyses}

Finally, we conducted adjacent two and three SNP haplotype analyses for chronic bronchitis in both cohorts (table 4). In the ICGN data, 11 adjacent SNP combinations showed significant associations with chronic bronchitis $(0.0029 \leqslant$ global p-value $\leqslant 0.0457$ and $0.0015 \leqslant$ specific $p$-value $\leqslant 0.0286)$. Haplotypes 4-5 (rs16840252-rs231775) and 4-5-6 (rs16840252-rs231775rs231777) for chronic bronchitis remained significant after Bonferroni correction for multiple testing. Similar results were observed in the COPD cases of the Bergen cohort, where we found nine haplotypes showing significant association with chronic bronchitis $(0.0282 \leqslant$ global p-value $\leqslant 0.0481$ and $0.0186 \leqslant$ specific $\mathrm{p}$-value $\leqslant 0.0385)$.

\section{DISCUSSION}

The most salient finding of our study is the replicated association of several SNPS in the CTLA4 gene with one of the most characteristic phenotypes of COPD, namely chronic bronchitis. These results suggest that CTLA4 is a novel genetic determinant of chronic bronchitis among COPD cases.

\section{Previous studies}

Thus far, the most clearly documented genetic risk factor for COPD is severe $\alpha_{1}$-antitrypsin deficiency. Many previous studies have identified a variety of genetic variants in other genes that were associated with COPD, but these results have not often been replicated in other cohorts. To our knowledge, no previous study has investigated CTLA4 in relation to
COPD-related phenotypes. Our results show that CTLA4 is associated with chronic bronchitis among COPD cases. Interestingly, the CTLA4 gene is located near the region of chromosome $2 q$ with linkage to COPD-related phenotypes [912]. It is noteworthy that we did not find associations of CTLA4 SNPs with the presence of COPD or the severity of airflow limitation assessed by FEV1 and FEV1/FVC.

\section{Potential mechanisms}

T-lymphocytes play a key role in the pathogenesis of COPD and chronic bronchitis. CTLA4 is a crucial gene in the control of T-cell activation [20]. We speculate that the CTLA4 polymorphisms may compromise the regulatory function of CTLA4, and that a weakened inhibitory function of CTLA4 could facilitate T-cell proliferation and differentiation, thus leading to airway inflammation and the symptoms of chronic cough and phlegm production that define chronic bronchitis [20]. This would be in keeping with the recently proposed hypothesis of an abnormal acquired immune response in the pathogenesis of COPD [36] and would be supported by the following documented findings. CTLA4 controls a potentially damaging expansion of T-cells by arresting activated T-cells [20]. However, this CTLA-mediated anergic check-point can be released by simultaneous stimulation of TCR/CD28 and the polarising cytokines, interleukin (IL)-12 and IL-4, which lead to CD4+ T-cell differentiation towards T-helper cell (Th) type 1 and 2, respectively [20]. Th1 CD4+ cells and cytotoxic T-cell-1 CD8+ cells are increased in COPD and chronic bronchitis [13, $15,16]$. These cells secrete interferon (IFN)- $\gamma$ and tumour necrosis factor- $\alpha$, which activate macrophages. Activated macrophages secrete IL-12, which in turn activates the transcription factor STAT4 [37]. There is an increased number of activated STAT4 and IFN- $\gamma^{+}$cells in bronchial biopsies and bronchoalveolar lavage fluid in patients with COPD, and their increasing expression correlates with decreasing lung function 
[37]. If STAT4 signals in the lung overcome the inhibitory role of CTLA4 [38] or the latter is genetically compromised, tissue inflammation and damage may ensue and COPD including chronic bronchitis may develop. It is of interest that one of the SNPs associated with chronic bronchitis (rs231775) is a nonsynonymous coding polymorphism, which results in a change of the amino acid at position 17 from Thr to Ala. This polymorphism is in the signal peptide and is absent from the mature protein. It could affect the efficiency of post-translational modifications other than cleavage, potentially resulting in inefficient processing in the endoplasmic reticulum, leading to reduced surface expression [39]. There are several reports showing the functional effect of this polymorphism on T-cell function. MÄURER et al. [40] examined the T-cell response from healthy donors homozygous for either A or G at nucleotide position 49 (amino acid position 17). They found that the $G$ allele affected the CTLA4 downregulation of T-cell activation. In addition, blockade of CTLA4 ligation using soluble anti-CTLA4 monoclonal antibody did not augment proliferation as much in T-cells from G/G-expressing individuals as from A/A-expressing ones. Similar results have also been shown by Sun et al. [41]. All these studies show consistent results and it has to be noted that the association that we identified with chronic bronchitis is with the $\mathrm{G}$ allele. Thus, this polymorphism might result in reduced expression of CTLA4, which could lead to the development of chronic bronchitis. However, we note that this variant may also be a marker for an un-genotyped variant in tight LD with this variant in the CTLA4 gene.

\section{Strengths and limitations of our study}

Our study has several strengths and limitations that deserve comment. Among the former is the fact that we can exclude population stratification because family-based association analyses, as we performed in the ICGN study, are robust against population stratification, and the genomic control methods used in our case-control cohort did not detect significant population stratification. A second strength of our experimental design is that the two study populations were phenotyped for chronic bronchitis using the same questionnaire, thus reducing possible phenotype heterogeneity. Thirdly, we replicated the genetic associations found in the ICGN cohort in an independent population, an approach that is considered the gold standard for demonstrating the relevance of a candidate gene for complex diseases [42, 43]. Finally, two SNPs (rs231775 and rs3087243) were still significantly associated with chronic bronchitis after conservative correction for multiple comparisons, thus reinforcing the validity of our observations.

Conversely, our study has a limitation that requires discussion. We did not find significant associations of CTLA4 SNPs with the presence of COPD or the degree of airflow limitation assessed by FEV1 and FEV1/FVC. It is possible that the multiple mechanisms that could contribute to airflow obstruction in COPD impaired our ability to find significant associations with COPD; alternatively, it is possible that CTLA4 is a genetic determinant of only chronic bronchitis, and not of airflow obstruction.

In conclusion, we performed a genetic association study and identified variants in the CTLA4 gene that were associated with chronic bronchitis in COPD cases, although not with COPD directly. Although the precise role of CTLA4 in the pathogenesis of COPD including chronic bronchitis is still to be elucidated, our findings open a new avenue for COPD research.

\section{STATEMENT OF INTEREST}

Statements of interest for G. Zhu, P. Bakke, H. Coxson, E.K. Silverman and S.G. Pillai can be found at www.erj.ersjournals.com $/ \mathrm{misc} /$ statements.dtl

\section{ACKNOWLEDGEMENTS}

Authors gratefully acknowledge the assistance of the site coordinators for the family and case control collections; M. Hall, S. Hammond, R. Taylor, S. Alalouf and S. Subramanian of GlaxoSmithKline for data management support; T. Leonard, R. Vessey, D. Hay, M. Barnette, J. Snapper and W. Anderson of GlaxoSmithKline for helpful discussions. CIBER Enfermedades Respiritorias is an initiative of Instituto de Salud Carlos III (Ministerio de Ciencia e Innovación, Madrid, Spain).

The ICGN investigators were as follows: P.M.A. Calverley (University of Liverpool, UK); C.F. Donner (Division of Pulmonary Disease, S. Maugeri Foundation, Veruno, Italy); R.D. Levy and P.D. Paré (University of British Columbia, Vancouver, BC, Canada); B.J. Make (National Jewish Medical and Research Centre, Denver, CO, USA), S.I. Rennard (University of Nebraska, Omaha, NE, USA); J. Vestbo (Dept of Cardiology and Respiratory Medicine, Hvidovre Hospital, Copenhagen, Denmark); and E.F.M. Wouters (University Hospital Maastricht, the Netherlands).

\section{REFERENCES}

1 Pauwels RA, Buist AS, Calverley PM, et al. Global strategy for the diagnosis, management, and prevention of chronic obstructive pulmonary disease. NHLBI/WHO Global Initiative for Chronic Obstructive Lung Disease (GOLD) Workshop summary. Am J Respir Crit Care Med 2001; 163: 1256-1276.

2 Hanrahan JP, Sherman CB, Bresnitz EA, et al. Cigarette smoking and health. Am J Respir Crit Care Med 1996; 153: 861-865.

3 Rennard SI, Vestbo J. COPD: the dangerous underestimate of $15 \%$. Lancet 2006; 367: 1216-1219.

4 Redline S, Tishler PV, Rosner B, et al. Genotypic and phenotypic similarities in pulmonary function among family members of adult monozygotic and dizygotic twins. Am J Epidemiol 1989; 129: 827-836.

5 Webster PM, Lorimer EG, Man SF, et al. Pulmonary function in identical twins: comparison of nonsmokers and smokers. Am Rev Respir Dis 1979; 119: 223-228.

6 Kauffmann F, Tager IB, Munoz A, et al. Familial factors related to lung function in children aged 6-10 years. Results from the PAARC epidemiologic study. Am J Epidemiol 1989; 129: 1289-1299.

7 Lebowitz MD, Knudson RJ, Burrows B. Family aggregation of pulmonary function measurements. Am Rev Respir Dis 1984; 129: $8-11$.

8 McCloskey SC, Patel BD, Hinchliffe SJ, et al. Siblings of patients with severe chronic obstructive pulmonary disease have a significant risk of airflow obstruction. Am J Respir Crit Care Med 2001; 164: 1419-1424.

9 Silverman EK, Mosley JD, Palmer LJ, et al. Genome-wide linkage analysis of severe, early-onset chronic obstructive pulmonary disease: airflow obstruction and chronic bronchitis phenotypes Hum Mol Genet 2002; 11: 623-632.

10 Silverman EK, Palmer LJ, Mosley JD, et al. Genomewide linkage analysis of quantitative spirometric phenotypes in severe earlyonset chronic obstructive pulmonary disease. Am J Hum Genet 2002; 70: 1229-1239. 
11 Palmer LJ, Celedón JC, Chapman HA, et al. Genome-wide linkage analysis of bronchodilator responsiveness and post-bronchodilator spirometric phenotypes in chronic obstructive pulmonary disease. Hum Mol Genet 2003; 12: 1199-1210.

12 Malhotra A, Peiffer AP, Ryujin DT, et al. Further evidence for the role of genes on chromosome 2 and chromosome 5 in the inheritance of pulmonary function. Am J Respir Crit Care Med 2003; 168: 556-561.

13 Turato G, Zuin R, Saetta M. Pathogenesis and pathology of COPD. Respiration 2001; 68: 117-128.

14 Barnes PJ, Shapiro SD, Pauwels RA. Chronic obstructive pulmonary disease: molecular and cellular mechanisms. Eur Respir J 2003; 22: 672-688.

15 Sun G, Stacey MA, Vittor E, et al. Cellular and molecular characteristics of inflammation in chronic bronchitis. Eur J Clin Invest 1998; 28: 364-372.

16 Gamble E, Burns W, Zhu J, et al. Variation of CD8+ T-lymphocytes around the bronchial internal perimeter in chronic bronchitis. Eur Respir J 2003; 22: 992-995.

17 Tivol EA, Borriello F, Schweitzer AN, et al. Loss of CTLA-4 leads to massive lymphoproliferation and fatal multiorgan tissue destruction, revealing a critical negative regulatory role of CTLA-4. Immunity 1995; 3: 541-547.

18 Ueda H, Howson JMM, Esposito L, et al. Association of the T-cell regulatory gene CTLA4 with susceptibility to autoimmune disease. Nature 2003; 423: 506-511.

19 Mohrs M, Lacy DA, Locksley RM. Stat signals release activated naïve Th cells from an anergic checkpoint. J Immunol 2003; 170: 1870-1876.

20 Luhder F, Chambers C, Allison JP, et al. Pinpointing when T cell costimulatory receptor CTLA-4 must be engaged to dampen diabetogenic T cells. Proc Natl Acad Sci USA 2000; 97: 12204-12209.

21 Howard TD, Postma DS, Hawkins GA, et al. Fine mapping of an IgE-controlling gene on chromosome 2q: analysis of CTLA4 and CD28. J Allergy Clin Immunol 2002; 110: 743-751.

22 Muntha-Kaas MC, Carlsen KH, Helms PJ, et al. CTLA-4 polymorphisms in allergy and asthma and the TH1/TH2 paradigm. J Allergy Clin Immunol 2004; 114: 280-287.

23 Zhu G, Warren L, Aponte J, et al. The SERPINE2 gene is associated with chronic obstructive pulmonary disease in two large populations. Am J Respir Crit Care Med 2007; 176: 167-173.

24 Patel BD, Coxson HO, Pillai SG, et al. Airway wall thickening and emphysema show independent familial aggregation in COPD. Am J Respir Crit Care Med 2008; 178: 500-505.

25 Pillai SG, Zhu G, Gulsvik A, et al. SERPINE2 and COPD. Am J Respir Crit Care Med 2007; 176: 726.

26 Barrett JC, Fry B, Maller J, et al. Haploview: analysis and visualization of LD and haplotype maps. Bioinformatics 2005; 21: 263-265.
27 Internation HapMap Project. www.hapmap.org Date last updated: April, 2: 2009.

28 Lange C, DeMeo D, Silverman EK, et al. PBAT: tools for familybased association studies. Am J Hum Genet 2004; 74: 367-369.

29 O'Connell JR, Weeks DE. PedCheck: a program for identification of genotype incompatibilities in linkage analysis. Am J Hum Genet 1998; 63: 259-266.

30 Horvath S, Xu X, Laird NM. The Family Based Association Test method: strategies for studying general genotype-phenotype associations. Eur J Hum Genet 2001; 9: 301-306.

31 Nyholt DR. A simple correction for multiple testing for single nucleotide polymorphisms in linkage disequilibrium with each other. Am J Hum Genet 2004; 74: 765-769.

32 Horvath S, Xu X, Lake SL, et al. Family-based tests for associating haplotypes with general phenotype data: application to asthma genetics. Genet Epidemiol 2004; 26: 61-69.

33 Schaid DJ, Rowland CM, Tines DE, et al. Score tests for association between traits and haplotypes when linkage phase is ambiguous. Am J Hum Genet 2002; 70: 425-434.

34 Devlin B, Roeder K. Genomic control for association studies. Biometrics 1999; 55: 997-1004.

35 Gabriel SB, Schaffner SF, Nguyen H, et al. The structure of haplotype blocks in the human genome. Science 2002; 296: 22252229.

36 Agusti A, MacNee W, Donaldson K, et al. Hypothesis: does COPD have an autoimmune component? Thorax 2003; 58: 832-834.

37 Di Stefano A, Caramori G, Capelli A, et al. STAT4 activation in smokers and patients with chronic obstructive pulmonary disease. Eur Respir J 2004; 24: 78-85.

38 Cosio MG. Autoimmunity, T-cells and STAT-4 in the pathogenesis of chronic obstructive pulmonary disease. Eur Respir J 2004; 24: 3-5.

39 Anjos S, Nguyen A, Ounissi-Benkalha H, et al. A common autoimmunity predisposing signal peptide variant of the cytotoxic T-lymphocyte antigen 4 results in inefficient glycosylation of the susceptibility allele. J Biol Chem 2002; 277: 46478-46486.

40 Mäurer M, Loserth S, Kolb-Maurer A, et al. A polymorphism in the human cytotoxic T-lymphocyte antigen 4 (CTLA4) gene (exon 1 +49) alters T-cell activation. Immunogenetics 2002; 54: 1-8.

41 Sun $\mathrm{T}$, Zhou $\mathrm{Y}$, Yang $\mathrm{M}$, et al. Functional genetic variations in cytotoxic T-lymphocyte antigen 4 and susceptibility to multiple types of cancer. Cancer Res 2008; 68: 7025-7034.

42 Tabor HK, Risch NJ, Myersv RM. Candidate-gene approaches for studying complex genetic traits: practical considerations. Nat Rev Genet 2002; 3: 1-7.

43 Hattersley AT, McCarthy MI. A question of standards: what makes a good genetic association study? Lancet 2005; 366: 13151323. 